\title{
Controvérsias na Associação entre Diabetes Mellitus Tipo 1 e Asma
}

\begin{abstract}
revisão
CRÉSIO Alves

ANDRÉA BORGES DINIZ

Mateus BoAventuRa SOUZA

EDUARDO V. PONTE

MARIa ILMA ARAÚJo

Faculdade de Medicina, Universidade Federal da Bahia, Salvador, BA.

Recebido em 19/12/06

\section{RESUMO}

Objetivo: Revisão crítica da literatura sobre a associação entre asma e diabetes mellitus tipo 1 (DM1). Fonte dos dados: Pesquisa bibliográfica na base de dados MEDLINE e LILACS nos últimos vinte anos. Síntese dos dados: Muitos estudos mostram associação inversa entre asma, atopia e o risco de desenvolver DM1. De acordo com a "Hipótese da Higiene", o risco de doenças alérgicas diminui com infecções precoces na infância no sentido de afastar-se do perfil Th2, predominante ao nascimento, em direção ao fenótipo Th1. No entanto, outros trabalhos demonstram associação positiva ou ausência de associação entre DM1 e alergias. Existe a possibilidade de fatores ambientais contribuírem para ocorrência de doenças mediadas por células Th1 e Th2 no mesmo indivíduo, por provável deficiência de mecanismos imunomodulatórios mediados pela interleucina-10 e células regulatórias. Conclusão: As informações sobre a associação inversa entre doenças mediadas por resposta Th1 (por exemplo, DM1), e aquelas mediadas por resposta Th2 (por exemplo, alergias) são conflitantes, requerendo mais estudos para esclarecer esta questão. (Arq Bras Endocrinol Metab 2007;51/6:930-937)

Descritores: Diabetes melito tipo 1; Asma; Hiperreatividade brônquica; Atopia

\section{ABSTRACT}

\section{Controversies in the Association Between Type 1 Diabetes and Asthma.}

Objective: Critical review of the literature to investigate the relationship between asthma and type 1 diabetes mellitus (DM1). Source of data: Bibliography search in MEDLINE and LILACS databases in the last twenty years. Summary of data: Several studies demonstrate an inverse relationship between asthma, atopic diseases and the risk to develop DM1. According to the "Hygiene Hypothesis", the risk of allergic diseases decreases with infections early in childhood, towards distance of Th2 profile, common at birth, to the Th1 phenotype. Other articles described lack of association or positive association between DM1 and allergies. There is a possibility of environmental factors interfering in the development of disorders mediated by Th1 and Th2 cells, in the same individual, due to the absence of immunomodulatory mechanisms mediated by interleukin-10 and regulatory cells. Conclusion: The existing information about the inverse association between Th1-mediated diseases (e.g., DM1), and those that are Th2-mediated (e.g., allergies) are conflicting requiring more investigation to explain this question. (Arq Bras Endocrinol Metab 2007;51/6:930-937)
\end{abstract}

Revisado em 12/03/07

Aceito em 30/03/07

Keywords: Type 1 diabetes; Asthma; Bronchial reactivity; Atopy 
D OIS SUBTIPOS DE LINFÓCITOS T CD4+ auxiliares ou "helper" (Thl e Th2) participam da regulação das respostas imunológicas (1). Células Thl produzem interferon gama (IFN- $\gamma)$, interleucina 2 (IL-2) e fator de necrose tumoral (TNF- $\alpha)$, enquanto células Th2 produzem principalmente IL-4, IL-5 e IL-13 (1,2). Os linfócitos Thl estão envolvidos com a proteção do hospedeiro contra infecções por agentes intracelulares e participam da patogênese da maioria das doenças auto-imunes. Os Th2 protegem contra infecções por agentes extracelulares e participam da patogênese das doenças atópicas (2).

De acordo com o paradigma Th1/Th2, essas células inibem-se reciprocamente, com a produção de suas citocinas específicas $(2,3)$. Assim, pode-se especular que a prevalência de enfermidades mediadas por células do tipo Thl (por exemplo, diabetes mellitus tipo 1) seja menor em indivíduos com doenças mediadas por células Th2 (por exemplo, asma) e viceversa. Com base nesse conceito, fatores que predispõem a doenças atópicas podem oferecer proteção contra doenças auto-imunes $(4,5)$.

Entretanto, esta forma polarizada de classificação da resposta imune, além de ser muito simplista, não explica os relatos de associação positiva e mesmo de não-associação entre diabetes mellitus tipo 1 (DMl) e asma (3).

Este artigo tem por objetivo realizar uma revisão crítica da literatura para investigar a associação entre asma e diabetes mellitus tipo 1 .

\section{ASPECTOS IMUNOLÓGICOS DO DIABETES MELLITUS TIPO 1 E DA ASMA}

\section{Diabetes mellitus tipo 1}

Diabetes mellitus tipo l é uma doença auto-imune mediada por linfócitos Thl auto-reativos que infiltram as ilhotas de Langerhans causando inflamação (insulite) e destruição celular em indivíduos geneticamente predispostos (6,7). Quando a população destas células produtoras de insulina é reduzida a menos de 80-90\%, tem início a hiperglicemia e os sintomas clínicos da doença.

Várias evidências apóiam o papel da imunidade celular (células T) na patogênese do DMl: presença de insulite, diminuição da progressão da doença com o uso de drogas imunossupressoras dirigidas contra as células $\mathrm{T}$, preservação das células beta com o uso de anticorpos monoclonais anti-CD3, destruição de segmentos pancreáticos obtidos a partir de transplante entre gêmeos idênticos e presença de células $\mathrm{T}$ auto-reativas circulantes
(6). De modo simples, a exposição ao sistema imune de proteínas das células beta (por exemplo, decarboxilase do ácido glutâmico [GAD], IA-2 [tirosino-fosfatase], próinsulina) a partir, por exemplo, de uma agressão viral faz com que esses componentes sejam apresentados às células T pelos macrófagos e células dentríticas, levando ao desenvolvimento da insulite (6).

A imunidade humoral, produção de anticorpos contra componentes das células beta (anti-GAD, antiIA2, anti-insulina) não parece ser essencial na patogênese do DMl. Isto é demonstrado pela ocorrência de DMl em um paciente com deficiência hereditária de linfócitos $\mathrm{B}$ e pela falta de resposta às terapias direcionadas contra a resposta humoral (plasmaferese, imunoglobulina endovenosa etc.) (6).

O desencadeamento da reação inflamatória parece depender tanto de fatores genéticos quanto ambientais (8-10). Dentre os fatores ambientais envolvidos na gênese do $\mathrm{DMl}$, destacam-se os vírus, proteínas do leite de vaca e toxinas (estreptozotocina, aloxana) (10).

Em relação aos fatores genéticos, aproximadamente vinte loci genéticos, denominados IDDM-1 a IDDM-20, foram identificados como possíveis candidatos a genes de susceptibilidade para o DMl (11). Os mais estudados são IDDM-1, IDDM-2 e IDDM-12.

O lócus IDDM-1, localizado no cromossomo $6 \mathrm{p} 21$, é o mais importante, respondendo por aproximadamente $30-50 \%$ da agregação familiar da doença (9). Esse gene codifica moléculas HLA de classe II presentes na superfície das células apresentadoras de antígenos (células dendríticas, macrófagos e linfócitos B) que participam do processo imune apresentando antígenos aos linfócitos $\mathrm{CD}^{+}(8,9)$. Em brasileiros com DMl, os alelos HLA de susceptibilidade (HLA$D R B I * 03$ [-DR3], $-D R B 1 * 04$ [-DR-4], $-D Q B 1 * 0201 \mathrm{e}$ $D Q B 1 * 0302)$ e proteção (HLA-DQBI*0602 e $D Q B I * 0301)$ apresentam distribuição semelhante ao de populações de caucasianos (9).

O IDDM-2, localizado no cromossomo $11 \mathrm{pl} 5$ numa área próxima ao gene da insulina, contribui com aproximadamente $10 \%$ da susceptibilidade para o DMl (11). Esse gene contém seqüências repetidas de DNA denominadas VNTR (variable number of tandem repeats), as quais são divididas em três classes de alelos. Os alelos de classe I são associados à susceptibilidade ao DMl e os de classe II são considerados protetores. O mecanismo pelo qual as variações de VNTR se relacionam ao risco de desenvolvimento do DMl ainda é desconhecido.

No lócus IDDM-12, localizado no cromossomo 2q33, encontra-se o gene CTLA-4 (cytotoxic $T$ 
lymphocyte-associated antigen), que codifica receptores co-estimuladores nas células T levando à sua ativação (12). Polimorfismos desse gene, como a associação com a variante Thrl7Al (substituição da alanina por treonina no aminoácido 17), confere um risco 1,3 vezes maior de desenvolver DMl (11). Entretanto, diferenças étnicas entre populações e sua fraca associação limitam a utilidade de sua análise (12).

\section{Asma}

A asma é uma desordem genética complexa que possui vários fenótipos. Suas principais características são hiper-reatividade brônquica, obstrução reversível do fluxo de ar e inflamação crônica das vias aéreas (13). A interação entre fatores ambientais e fatores genéticos leva ao desenvolvimento da asma no hospedeiro susceptível (14). A principal causa da inflamação crônica das vias aéreas é a alergia. No Brasil, os antígenos de ácaros e de baratas são os mais importantes (15).

$\mathrm{Na}$ asma, a resposta imune é predominantemente do tipo Th2. Biópsia brônquica e estudos de lavado alveolar de pacientes asmáticos mostram predominância de RNA mensageiro para IL-3, IL-4 e IL-5 em relação a não-asmáticos (16). Uma vez inalado, o aeroalérgeno é apresentado aos linfócitos TCD4+, que, na presença da IL-4, diferencia-se em células do tipo Th2. Estas células, através da produção de algumas citocinas, a exemplo de IL-4 e IL-13, estimulam os linfócitos B a produzirem imunoglobulina $\mathrm{E}$ ( $\mathrm{IgE}$ ) específica para aquele alérgeno. Em seguida, a IgE se liga a receptores de mastócitos na via aérea e, ao ser estimulada, em novo contato, pelo aeroalérgeno específico, faz com que mastócitos liberem histamina e leucotrieno, dentre outros mediadores, causando inflamação e obstrução da via aérea. Esta fase imediata da inflamação é seguida pela fase tardia caracterizada pela participação de mastócitos, macrófagos, linfócitos, eosinófilos e células epiteliais (13).

\section{ASSOCIAÇÃO ENTRE DIABETES MELLITUS TIPO 1 E ASMA}

\section{Contribuições da epidemiologia}

Os estudos clínico-epidemiológicos sobre a associação entre asma e DMl mostram resultados conflitantes, isto é, associações negativas, positivas e ausência de associações.

\section{Associação negativa}

São vários os estudos que sugerem haver uma associação inversa entre DMl e alergias, ou seja, as doenças alérgicas protegeriam contra o desenvol- vimento de DMl. Hermansson e cols. (17), estudando os registros médicos de 128 crianças suecas e diabéticas, encontraram associação negativa entre DMl e doenças atópicas. Meerwald e cols. (2) e Mattila e cols. (4) descreveram menor freqüência de asma em indivíduos com diabetes. No estudo de Mattila e cols., também foi encontrada associação inversa entre DMl e dermatite atópica. Além de dados sobre a menor freqüência de doenças atópicas em indivíduos com diabetes melito tipo 1, Douek e cols. (18) observaram associação inversa entre os sintomas de asma e DMl, e discutiram que tal associação poderia ter uma base genética ou ser devido a fatores ambientais agindo na vida intra-uterina ou durante a infância. Em um grande estudo multicêntrico (EURODIAB Substudy 2 Group, 2000), foi relatada menor prevalência de doenças atópicas, particularmente asma, em crianças com diabetes, o que reforça haver uma proteção concedida pelas doenças alérgicas contra o desenvolvimento de DMl (19). Olensen e cols. (20) demonstraram associação inversa entre dermatite atópica e DMl. Associações inversas também foram encontradas para asma, febre Q e DMl, embora nesses dois últimos casos os resultados não tenham sido estatisticamente significantes. Rosenbauer e cols. (3) descreveram que o eczema atópico foi menos freqüente em diabéticos do que em não-diabéticos. Além disso, a atopia associouse a menor risco de desenvolver DMl, demonstrando que o aparecimento precoce do eczema atópico na infância parece proteger contra o desenvolvimento de DM1. Cardwell e cols. (21), num estudo de metanálise, relataram redução na prevalência de asma em crianças com DMl. Já para outras doenças atópicas (eczema atópico e rinite, por exemplo), os resultados não foram conclusivos.

A determinação da seqüência em que as enfermidades atópicas e auto-imunes surgem é importante, pois a presença de uma enfermidade mediada pela resposta do tipo Th2 pode reduzir o risco de outra mediada por Thl, mesmo que o processo inverso não ocorra (5). Além disso, o efeito protetor das doenças atópicas sobre o desenvolvimento de DMl pode ser dependente da idade. No EURODIAB Substudy Group 2 (17), este efeito foi observado em crianças de 10 a 14 anos, mas não nos grupos de $0-4$ e de 5-9 anos.

\section{Associação positiva}

A partir da segunda metade do século XX, a prevalência de asma e DMl na infância tem aumentado na maior parte do ocidente, sugerindo um fator epidemiológico comum (22). 
Na Europa, o número de casos de DMl vem aumentando a cada ano (23). Na Suíça, houve crescimento de 5,1\% entre 1991 e 1999 (24). As taxas de incidência variam em diferentes partes do mundo, sugerindo a interferência de um fator genético ou ambiental. Enquanto na Finlândia a incidência chega a $35 / 100.000$ habitantes/ano, nenhum país abaixo do Equador apresenta incidência maior que 20/100.000 habitantes/ano (25). No Brasil, a incidência de DMl varia de 7,6/100.000 habitantes/ano em São Paulo (26) a 12/100.000 habitantes/ano no Rio Grande do Sul (25).

Paralelamente a isto, o crescimento da ocidentalização também está associado ao rápido aumento na prevalência de desordens atópicas antes incomuns (27). No Brasil, a prevalência de chiado (asma) nos últimos 12 meses, em adolescentes entre 13 e 14 anos residentes em grandes centros urbanos, foi de 20 a $25 \%$, o que o faz ser considerado um dos países com maior prevalência da doença na América Latina (14).

Diferenças socioeconômicas parecem ser responsáveis por esse aumento na incidência de doenças atópicas e auto-imunes. Por exemplo: descendentes de paquistaneses residentes no Reino Unido têm um risco 10 vezes maior de desenvolver DMl quando comparados a indivíduos residentes em seu país de origem (28); na Irlanda, foi mostrada correlação positiva entre menor incidência de DMl e baixo nível socioeconômico (29) e a incidência de asma é maior em indivíduos residentes na antiga Alemanha Ocidental quando comparados aos da antiga Alemanha Oriental (30).

Tendo em vista as propriedades de regulação cruzada das células do tipo Thl e Th2, poder-se-ia imaginar que o crescimento na prevalência das doenças atópicas levaria a um declínio na prevalência das doenças auto-imunes e, ainda, que esses tipos de doenças seriam detectados em diferentes populações (31). No entanto, alguns locais com alta prevalência de doenças atópicas apresentam elevadas incidências de DMl (32), e a presença de DMl não protege contra atopia, uma vez que tem sido observados pacientes que apresentam as duas doenças concomitantemente.

Sheikh e cols. (1) encontraram associação positiva entre desordens alérgicas mediadas por resposta Th2 e distúrbios auto-imunes mediados por Thl. Em outro estudo, a presença de asma foi mais comum em crianças com DMl indicando um possível agente ambiental comum às duas doenças (31). Esses autores também mostraram co-existência de asma em crianças com desordens auto-imunes como doença celíaca e artrite reumatóide. Stene \& Nafsted (32) mostraram associação positiva entre asma e maior risco de DMl.
Simpson e cols. (33) observaram aumento significativo do risco de doenças alérgicas em pacientes com doenças auto-imunes mediadas por Thl.

\section{Ausência de associação}

Alguns estudos têm mostrado ausência de associação entre atopia e DMI. Strömberg e cols. (34) não observaram diferenças na prevalência de eczema, rinite alérgica, asma e urticária entre crianças com DMl e o grupo controle. A relação inversa entre os níveis de $\operatorname{IgE}$, um importante marcador de alergia, e o risco de desenvolver DMl não foi observada por Ziegler \& Bonifácio (35). Douek e cols. (18), comparando crianças com DMl e seus irmãos sem a doença, não encontraram associação do DMl com rinoconjuntivite alérgica. Sheikh e cols. (1) não observaram relação inversa entre atopia e doenças auto-imunes em população de adultos nos EUA. Segundo esses autores, os relatos de associação positiva podem ser resultado de vieses de informação e que acreditar na associação negativa seria uma simplificação da fisiopatologia dessas doenças. No estudo de Stene e cols. (5), asma e rinoconjuntivite alérgica não foram associadas com DMl.

\section{Contribuições da imunologia}

Existem algumas hipóteses para tentar explicar os mecanismos causais responsáveis pelas conflitantes formas de associação entre asma e DMl, são elas:

\section{Hipótese da higiene / Paradigma Th1/Th2}

A hipótese da higiene e o paradigma Thl/Th2 têm sido utilizados para explicar a associação negativa entre DMl e asma. A hipótese da higiene postula que a diminuição dos estímulos ambientais (como redução do número de infecções através das políticas de vacinação e de saneamento básico, antibioticoterapia e melhora do nível socioeconômico) tem favorecido ao predomínio do padrão Th2, explicando o aumento da prevalência de doenças alérgicas em indivíduos susceptíveis (36). O paradigma Thl/Th2 diz que doenças com elevada expressão de citocinas Th2 (enfermidades atópicas, infecções helmínticas) inibem a resposta Thl com redução do risco de desenvolver doenças auto-imunes, enquanto doenças com aumento de citocinas Thl (infecções virais e bacterianas) inibiriam a resposta Th2 e protegeriam contra atopia (33).

Entretanto, esta forma polarizada de classificação das respostas imunes (inibição recíproca das células Th1 e Th2) não explica a associação positiva entre DMl e asma. Por esta hipótese deveriam haver prevalências em sentido oposto, o que nem sempre é observado. 
Como entender esse aparente paradoxo? Como os mesmos estímulos ambientais podem promover o aumento da prevalência de doenças com orientações imunológicas distintas e potencialmente exclusivas? Se o paradigma Thl/Th2 fosse a única explicação para a patogenia dessas doenças, o aumento na prevalência de asma deveria ser associado a uma menor prevalência de DMl.

\section{Hipótese da higiene / Mecanismos regulatórios da resposta imune}

Uma vez que o paradigma Thl/Th2 é falho em explicar associações positivas e ausência de associações entre DMl e asma, outros mecanismos têm sido propostos para explicar como as infecções protegem concomitantemente contra doenças auto-imunes e doenças alérgicas. Dentre eles, destacam-se:

Células $\mathrm{T}$ regulatórias e citocinas: durante processos infecciosos, a interleucina-10, produzida por células regulatórias, a exemplo de células TCD4+ $\mathrm{CD}^{2} 5^{+} / \mathrm{Foxp}^{+}$(células que expressam a cadeia alfa do receptor da IL-2) e Trl (regulatory $T$ cell), além de células Th2, monócitos e macrófagos, reduz a progressão de doenças alérgicas e auto-imunes através da inibição da resposta imune do tipo Thl e Th2 (36-38).

A ação modulatória da IL-10 resulta da inibição da síntese de citocinas pró-inflamatórias, a exemplo do TNF, diminuição da atividade de neutrófilos e macrófagos, e redução da expressão de antígenos de histocompatibilidade (HLA) de classe II. Por outro lado, a IL-10 também inibe a produção de citocinas do tipo Th2 envolvidas na patogênese da asma (39), inibe a liberação de histamina pelos mastócitos/basófilo (40) e estimula a produção do anticorpo bloqueador IgG4 (41).

Entretanto, a maior produção da IL-10 não deve ser o único mecanismo protetor contra essas doenças, uma vez que camundongos NOD (non-obese diabetic) com deficiência na produção de IL-10 também são protegidos contra o DMl após serem infectados com microbactérias (42).

Outras possibilidades de imunomodulação seriam a maior produção do TGF- $\beta$ (transforming growth factor beta), que através do contato célulacélula modularia a resposta imune (38), e a indução de células TNK (natural killer). Células TNK vêm sendo implicadas na regulação de processos auto-imunes no homem e em camundongos. Estas células, quando ativadas, levam à rápida produção tanto de IFN- $\gamma$ quanto de IL4, o que capacita essas células para mediar tanto a resposta inflamatória como a antiinflamatória.

Pacientes com DMl, lupus eritematoso sistêmico, esclerodermia, esclerose múltipla e artrite reumatóide possuem baixos números de células TNK periférica, e a melhora clínica nessas doenças tem sido associada com a mudança do perfil das células Thl para Th2 (43). Enquanto muitos autores concordam que as células TNK contribuem para a prevenção das doenças auto-imunes, a exemplo do DMl, pelo menos em modelo de camundongos NOD, nos quais exercem uma complexa regulação da resposta imune (44-47), outros estudos referem que estas células não interferem com a doença (48) ou que podem contribuir para o agravamento da mesma (49).

Competição antigênica: por esse mecanismo, a resposta imune a um antígeno é diminuída pela resposta imune concomitante a outro antígeno, podendo afetar a resposta imune tanto a doenças alérgicas como a auto-imunes (50). Nesta situação, a estimulação antigênica desencadeadora de uma doença auto-imune (p.ex., DMl) poderia, por exemplo, inibir a resposta antigênica causadora de atopia.

Receptores Toll-like: ao se ligarem a antígenos bacterianos, esses receptores estimulariam células mononucleares a produzir citocinas, algumas das quais inibiriam a resposta alérgica e auto-imune (38). Este mecanismo já foi demonstrado como protetor no desenvolvimento de diabetes no camundongo NOD (38).

\section{Hipótese da higiene / Infecções por helmintos}

Devido à sua grande prevalência no Brasil e outros países em desenvolvimento, as infecções por helmintos merecem um tópico especial, uma vez que elas podem ser um dos fatores que contribuem para inibir $o$ desenvolvimento tanto de asma como de DMl (36).

Estudos com Schistosoma e Onchocerca volvulus mostram que esses parasitas inibem o desenvolvimento de doenças atópicas pela maior secreção de IL-10 por células regulatórias ou Th2, e pelo aumento dos níveis de IL-4, levando a excessiva produção de IgE policlonal com saturação de seus receptores nos mastócitos e/ou redução da produção de $\mathrm{IgE}$ específica para o alérgeno $(15,39)$. Infecções por Schistosoma mansoni e $S$. haematobium inibem a reatividade cutânea a aerolégenos e diminuem a prevalência e gravidade da asma (15,51). Camundongos NOD infectados por $S$. mansoni têm menor incidência de diabetes insulinodependente e a administração de antígenos de ovos de Shistosoma aumenta a resposta Th2 nesses animais (52). Porém, outros tipos de helmintos parecem não ser igualmente protetores contra atopia. Os dados referentes à associação entre asma e infecções por Ascaris lumbricoides, por exemplo, são contraditórios. Alguns estudos mostram associação negativa, isto é, efeito protetor da helmintíase $(53,54)$, e outros, associação positiva (55). Outro helminto, o Enterobius 
vermiculares, também parece exercer efeitos imunomodulatórios, inibindo o desenvolvimento de diabetes em camundongos NOD (36). Portanto, a redução da exposição a essas infecções levaria a menor produção de IL10 e outros fatores imunes que, por sua vez, aumentariam o risco de atopia e doenças auto-imunes (56). Para explicar os resultados discrepantes do efeito imunomodulador de diferentes helmintos sobre doenças atópicas e auto-imunes, existem várias hipóteses: local onde o helminto vive no nosso organismo (Ascaris na luz intestinal e o Schistosoma nas vênulas da veia porta), se o helminto tem ciclo pulmonar, intensidade da infecção, se a infecção é aguda ou crônica, co-infecção com outros agentes infecciosos, helmintos inclusive, e idade e origem (rural vs. urbana) da população estudada.

\section{IMPLICAÇÕES CLÍNICAS}

Se, de fato, o aumento crescente na incidência de asma e DMl for devido a fatores epidemiológicos comuns, espera-se que ocorra um número cada vez maior de indivíduos com essas condições, o que teria importantes implicações clínicas sobre vários aspectos:

Insulina inalável: a partir de 2007, está previsto o lançamento da insulina inalável. Nos estudos iniciais, diabéticos asmáticos absorveram menos insulina por via inalatória, necessitando de doses maiores do que diabéticos sem asma para obterem controle da glicemia (57).

Controle glicêmico: naqueles pacientes em que as duas doenças coexistem, o controle glicêmico é mais difícil de obter, uma vez que as drogas usadas no tratamento da asma (p.ex., beta-adrenérgicos, corticóides) são, na maioria das vezes, associadas à elevação da glicemia.

Custo emocional e financeiro: a associação de asma e DMl aumenta significativamente o custo emocional e financeiro para os portadores destas enfermidades.

Alterações pulmonares no DMl: van Gente e cols. (58) relataram maior resistência das vias aéreas em diabéticos quando comparados com valores de referência, o que poderia influenciar o prognóstico e tratamento de crianças com DMl e asma.

Antibioticoterapia: a associação entre DMl, asma e redução de infecções seria mais um fator, além da sua comprovada relação com resistência bacteriana, a recomendar o uso judicioso de antibióticos.

Vacinação: embora não existam evidências concretas sobre os efeitos maléficos da vacinação em desencadear doenças atópicas ou auto-imunes, mais estudos são necessários para investigar seu papel na fisiopatologia destas enfermidades (59).
Alternativas terapêuticas: as evidências de que antígenos parasitários podem modular a resposta imune e desta forma prevenir e/ou tratar doenças auto-imunes e alérgicas, através da indução da síntese de IL-10 e de outros mediadores regulatórios, têm levado à identificação desses antígenos e testes em modelos experimentais de doenças auto-imunes e alérgicas (25).

\section{CONSIDERAÇÕES FINAIS}

As informações disponíveis na literatura não permitem concluir sobre a real associação entre DMl e asma. Isto pode ser devido a vários fatores: amostras populacionais não-representativas, método de diagnóstico, idade dos participantes, desenho dos estudos, viés de seleção, memória e classificação, modelo de questionário utilizado e controle insuficiente de variáveis comuns. Ainda importante é o fato de a maioria dos estudos ter sido de base clínica com tamanho amostral insuficiente nos grupos caso e controle. É possível também que, em crianças com doenças crônicas, a asma seja mais freqüentemente diagnosticada e registrada. Um estudo de coorte prospectivo seria de fundamental importância para esclarecer a verdadeira associação entre asma e DMl e, assim, contribuir para avanços na prevenção e tratamento de doenças atópicas e auto-imunes.

\section{AGRADECIMENTOS}

Este trabalho foi parcialmente financiado pela FAPESB (Fundação de Amparo à Pesquisa do Estado da Bahia).

\section{REFERÊNCIAS}

1. Sheikh A, Smeeth L, Hubbard R. There is no evidence of an inverse relationship between $\mathrm{TH} 2$-mediated atopy and $\mathrm{TH} 1$ mediated autoimmune disorders: lack of support for the hygiene hypothesis. J Allergy Clin Immunol 2003; $111(1): 131-5$.

2. Meerwaldt $R$, Odink RJ, Landaeta $R$, Aarts $F$, Brunekreef $B$, Gerritsen J, et al. A lower prevalence of atopy symptoms in children with type 1 diabetes mellitus. Clin Exp All 2002;32:254-5.

3. Rosenbauer J, Herzig P, Giani G. Atopic eczema in early childhood could be protective against type 1 diabetes. Diabetologia 2003;46:784-8.

4. Mattila PS, Tarkkanen J, Saxen H, Pitkäniemi J, Karvonen M, Tuomilehto J. The Childhood Diabetes in Finland Study Group. Predisposition to atopic symptoms to inhaled antigens may protect from childhood type 1 diabetes. Diabetes Care 2002;25(5):865-8.

5. Stene LC, Joner G; Norwegian Childhood Diabetes Study Group. Atopic disorders and risk of childhood-onset type 1 diabetes in individuals. Clin Exp Allergy 2004;34:201-6. 
6. Roep BO. The role of T-cells in the pathogenesis of type 1 diabetes: from cause to cure. Diabetologia 2003;46:305-21.

7. Eiselein L, Schwartz HJ, Rutledge JC. The challenge of type 1 diabetes mellitus. ILAR J 2004;45(3):231-6.

8. Alves C, Souza T, Veiga S, Alves CO, Toralles MB. Importância do sistema de histocompatibilidade humano (HLA) em Pediatria. Pediatria (São Paulo) 2005;27:274-86.

9. Alves C, Meyer I, Vieira N, Toralles MB. Distribuição e freqüência de alelos e haplótipos HLA em brasileiros com diabetes melito tipo 1. Arq Bras Endocrinol Metab 2006;50:436-44.

10. Calliari PEL. Diabetes mellitus tipo 1. In: Junior GG, Calliari PEL (ed). Endocrinologia Pediátrica. $1^{a}$ ed. São Paulo: Atheneu, 2004. pp. 121-8.

11. Melo MB. Diabetes mellitus. In: Monte O, Longui CA, Calliari LE, Kochi C. Endocrinologia para o Pediátrica. $3^{a}$ ed. São Paulo: Atheneu, 2006. pp. 883-6.

12. Redondo MJ, Eisenbarth GS. Genetic control of autoimmunity in type 1 diabetes and associated disorders. Diabetologia 2002; $45: 605-22$

13. Hegele RG. The pathology of asthma: brief review. Immunopharmacol 2000;48:257-62.

14. ISAAC Steering Committee. Worldwide variation in prevalence of symptoms of asthma, allergic rhinoconjunctivitis, and atopic eczema: ISAAC. Lancet 1998;351:1225-32.

15. Medeiros Jr M, Carvalho EM, Araújo MI. Schistosoma mansoni infection, allergy, and asthma. Allergy Clin Immunonol Int - J World Allergy Org 2005;17:220-3.

16. Robinson DS, Hamid Q, Ying S, Tsicopoulos A, Barkans J, Bentley AM, et al. Predominant TH2-like bronchoalveolar Tlymphocyte population in atopic asthma. N Engl J Med 1992;326:298-304.

17. Hermansson B, Holmgren G, Samuelson G. Juvenile diabetes mellitus and atopy. Hum Hered 1971;21:504-8.

18. Douek IF, Leech NJ, Gillmor HA, Bingley PJ, Gale EAM. Children with type-1 diabetes and their unaffected siblings have fewer symptoms of asthma. Lancet 1999;353:1850.

19. EURODIAB Substudy 2 Study Group. Decreased prevalence of atopic diseases in children with diabetes. J Pediatr 2000;137(4):470-4.

20. Olesen AB, Juul S, Birkebaek N, Thestrup-Pedersen K. Association between atopic dermatitis and insulin-dependent diabetes mellitus: a case-control study. Lancet 2001;357:1749-52.

21. Cardwell CR, Shields MD, Carson DJ, Patterson CC. A metaanalysis of the association between childhood type 1 diabetes and atopic disease. Diabetes Care 2003:26(9):2568-74.

22. Tedeshi A, Airaghi L. Common risk factors in type diabetes and asthma. Lancet 2001;357:1622.

23. EURODIAB ACE Study Group. Variation and trends in incidence of childhood diabetes in Europe. Lancet 2000;355:873-6 [Erratum, Lancet 2000;356:1690].

24. Schoenle EJ, Lang-Muritano M, Gschwend S, Laimbacher J, Mullis PE, Torresani T, et al. Epidemiology of type 1 diabetes mellitus in Switzerland: steep rise in incidence in under 5 year old children in the past decade. Diabetologia 2001;44:286-9.

25. Lisboa HRK, Graebin R, Butzke L, Rodrigues CS. Incidence of type 1 diabetes mellitus in Passo Fundo, RS, Brazil. Braz J Med Biol Res 1998;31(12):1553-6.

26. Ferreira SR, Franco LJ, Vivolo MA, Negrato CA, Simões AC, Ventureli CR. Population-based incidence of IDDM in the state of São Paulo, Brazil. Diabetes Care 1993;16:701-4.

27. Upham JW, Holt PG. Environment and development of atopy. Curr Opin Allergy Clin Immunol 2005;5:167-72.

28. Staines A, Hanif S, Ahmed S, McKinsey PA, Shera S, Bodansky $\mathrm{HJ}$. Incidence of insulin-dependent diabetes mellitus in Karachi, Pakistan. Arch Dis Child 1997;76:121-3.

29. Paterson CC, Carson DJ, Hadden DR. Epidemiology of childhood IDDM in Northern Ireland 1989-1994: low incidence in areas with highest population density and most household crowding. Diabetologia 1996;39:1063-9.

30. von Mutius E, Martinez FD, Fritzch C, Nicolai T, Roell G, Thiemann HH. Prevalence of asthma and atopy in two areas of West Germany and East Germany. Am J Respir Crit Care Med 1994; 149:358-64.
31. Kero J, Gissler M, Hemminki E, Isolauri E. Could Th1 and Th2 diseases coexist? Evaluation of asthma incidence in children with coeliac disease, type 1 diabetes, or rheumatoid arthritis: a register study. J Allergy Clin Immunol 2001;108(5):781-3.

32. Setne LC, Nafstad P. Relation between occurrence of type 1 diabetes and asthma. Lancet 2001;357:607-8.

33. Simpson CR, Anderson WJA, Helms PJ, Taylor MW, Watson $L$, Prescott GJ, et al. Coincidence of immune-mediated diseases driven by Th1 and Th2 subsets suggests a common aetiology. A population-based study using computerized general practice data. Clin Exp All 2002;32:37-42.

34. Strömberg LGE, Ludvigsson GJ, Björkstén B. Atopic allergy and delayed hypersensitivity in children with diabetes. $\mathbf{J}$ Allergy Clin Immunol 1995;96(2):188-92.

35. Ziegler AG, Bonifacio $E$. No inverse relationship between total IgE levels and islet autoimmunity in children of parents with type 1 diabetes. Diabetes Care 2000;23(8):1205-6.

36. Gale EAM. A missing link in the hygiene hypothesis? Diabetologia 2002; $45: 588-94$.

37. Chai JG, Xue SA, Coe D, Addey C, Bartok I, Scott D, et al. Regulatory $T$ cells, derived from naive $C D 4+C D 25-T$ cells by in vitro Foxp3 gene transfer, can induce transplantation tolerance. Transplantation 2005;79(10):1310-6.

38. Bach JF. Mechanisms of disease: the effect of infections on susceptibility to autoimmune and allergic diseases. N Engl J Med 2002;347(12):911-20.

39. Araújo MI, Figueiredo JP, Almeida MC, Alcantara L, Carvalho EM, Medeiros Jr M. Impaired Th2 response to aeroallergen in asthmatics infected with Shistosoma mansoni. J Infect Dis 2004;99:27-32.

40. Royer B, Varadaradjalou S, Saas P, Guillosson JJ, Kantelip JP, Arock M. Inhibition of IgE-induced activation of human mast cells by IL-10. Clin Exp Allergy 2001;31(5):694-704.

41. Jeannin $P$, Lecoanet-Henchoz S, Delneste $Y$, Gauchat JF, Bonnefoy JY. Alpha-1 antitrypsin up-regulates human B cell differentiation selectively into lgE- and IgG4- secreting cells. Eur J Immunol 1998;28(6):1815-22.

42. Serreze DV, Chapman HD, Post CM, Johnson EA, Suarez-Pinzon WL, Rabinovitch A. Th1 to Th2 cytokine shifts in nonobese diabetic mice: sometimes an outcome, rather than the cause, of diabetes resistance elicited by immunostimulation. J Immunol 2001;166:1352-9.

43. Lalazar G, Preston S, Zigmond E, Yaacov AB, Ilan Y. Glycolipids as immune modulatory tools. Mini Rev Med Chem 2006;6(11):1249-53.

44. Cain JA, Smith JA, Ondr JK, Wang B, Katz JD. NKT cells and IFN-gamma establish the regulatory environment for the control of diabetogenic T cells in the nonobese diabetic mouse. J Immunol 2006;176(3):1645-54.

45. Cardell SL. The natural killer T lymphocyte: a player in the complex regulation of autoimmune diabetes in non-obese diabetic mice. Clin Exp Immunol 2006;143(2):194-202.

46. Chen YG, Choisy-Rossi CM, Holl TM, Chapman HD, Besra GS, Porcelli AS, et al. Activated NKT cells inhibit autoimmune diabetes through tolerogenic recruitment of dendritic cells to pancreatic lymph nodes. J Immunol 2005; 174(3):1196-204.

47. Duarte N, Stenstrom M, Campino S, Bergman ML, Lundholm $\mathrm{M}$, Holmberg D, et al. Prevention of diabetes in nonobese diabetic mice mediated by CD1d-restricted nonclassical NKT cells. J Immunol 2004;173(5):3112-8.

48. Rocha-Campos AC, Melki R, Zhu R, Deruytter N, Damotte D, Dy $\mathrm{M}$, et al. Genetic and functional analysis of the Nkt1 locus using congenic NOD mice: improved Valpha14-NKT cell performance but failure to protect against type 1 diabetes. Diabetes 2006:55(4):1163-70.

49. Griseri T, Beaudoin L, Novak J, Mars LT, Lepault F, Liblau R, et al. Invariant NKT cells exacerbate type 1 diabetes induced by CD8 T cells. J Immunol 2005;175(4):2091-101.

50. Liacopoulos HF, Eidinger D. Antigenic competition: a review of non-specific antigen-induced suppression. Prog Allergy 1975; $18: 133-68$.

51. van deen Biggelaar $A H$, van Ree $R$, Rodrigues $L C$, Lell $B$, Deelder AM, Kremser PG, et al. Decreased atopy in children infected with Schistosoma heamatobium: a role for parasiteinduced interleukin-10. Lancet 2000;356:1723-7. 
52. Cooke A, Tonks $P$, Jones FM, $\mathrm{O}^{\prime}$ Shea $\mathrm{H}$, Hutchings $\mathrm{P}$, Fulford AJ, et al. Infection with Schistosoma mansoni prevents insulin-dependent diabetes mellitus in non-obese mice. Parasite Immunol 1999;21:169-76.

53. Cooper PJ, Chico ME, Rodrigues LC, Ordonez M, Strachan D, Griffin GE. Reduced risk of atopy among school children infected with geohelminth parasites in a rural area of the Tropics. J Allergy Clin Immunol 2003;111:995-1000.

54. Dagoye D, Bekele Z, Woldemichael K, Nida H, Yimam M, Hall $A$, et al. Wheezing, allergy, and parasite infection in children in urban and rural Ethiopia. Am J Respir Critical Care Med 2003:167:1369-73

55. Palmer LJ, Celedón JC, Weiss ST, Wang B, Fang Z, Xu X. Ascaris lumbricoides infection is associated with increased risk of childhood asthma and atopy in rural China. Am J Resp Critical Care Med 2002;165:1489-93.

56. Holt PG. Parasites, atopy, and the hygiene hypothesis: resolution of a paradox? Lancet 2000;356:1493-9.

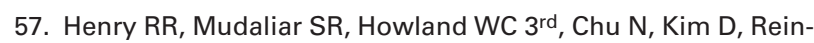
hardt RR. Inhaled insulin using the AER $x$ insulin diabetes management system in healthy and asthmatic subjects. Diabetes Care 2003;26(3):764-9.

58. van Gent, Brackel HJ, de Vroede M, van der Ent CK. Lung function abnormalities in children with type 1 diabetes. Respir Med 2002;96:976-8.

59. Offit PA, Hackett CJ. Addressing parents' concerns: do vaccines cause allergic or autoimmune diseases? Pediatrics 2003; 111:653-9.

Endereço para correspondência:

Crésio Alves

Rua Plínio Moscoso 222, apto. 601

40157-190 Salvador, BA

E-mail: cresio.alves@uol.com.br 